\title{
Farming God's Way: agronomy and faith contested
}

\author{
Harry Spaling ${ }^{1}\left[\right.$ Kendra Vander Kooy ${ }^{1}$
}

Accepted: 5 February 2019 / Published online: 28 February 2019

(c) The Author(s) 2019

\begin{abstract}
Farming God's Way (FGW) is a type of conservation agriculture (CA) that re-interprets the CA principles of no tillage, mulching and crop rotation using biblical metaphors such as God doesn't plow, God's blanket, and the Garden of Eden. Through faith-based networks, FGW has spread throughout Sub-Saharan Africa, and beyond, as a development intervention for improving food security, adapting to climate change, and restoring soil productivity for resource-poor farming households. This research identifies and compares the production, sustainability and faith claims of FGW to ascertain which claims are contested. A qualitative study of Canadian program managers with responsibilities for CA or FGW projects in Africa and smallholding FGW farmers in Kenya is employed using semi-structured interviews and focus groups. Production-related claims of improved soil moisture and climate change adaptation are generally consistent among program managers, farmers and the literature, but social claims of increased labour demand on women and religious claims of faith enhancing CA are contested. Findings show that female farmers unanimously contest the claim that their labour for weeding is increased under FGW. Similarly, FGW farmers contest the claim that faith inhibits adoption or innovation on the farm, reporting instead that FGW connects faith to their vocation, transforms why and how they farm, and changes mindsets for adopting faith-based CA.
\end{abstract}

Keywords Farming God's Way · Conservation agriculture $\cdot$ Sustainable farming $\cdot$ Religion and agriculture $\cdot$ Kenya

\begin{abstract}
Abbreviations
ACK Anglican church of Kenya

CA Conservation agriculture

FBO Faith-based organizations

FWG Farming God's Way
\end{abstract}

\author{
narrative, the socio-economic and \\ agro-ecological environments \\ cease to be structuring forces \\ of agronomic practice. Instead, \\ practising CA becomes a \\ righteous act, an act of faith ..." \\ (Andersson and Giller 2012, p. \\ 22).
}

Harry Spaling

harry.spaling@kingsu.ca

Kendra Vander Kooy

kendravanderkooy@gmail.com

1 Geography \& Environmental Studies Program, The King's University, 9125-50 St. NW, Edmonton, AB T6B 2H3, Canada
"God neither ploughs the soil nor destroys the beautiful blanket of mulch ... Do we presume to be better at farming than God?" (Dryden 2009, p. 9).

"Adopting CA (Conservation Agriculture) principles thus becomes a universal prerequisite for sustainable agriculture or, in the narrative of its Christian proponents, the only way to farm that is faithful to God. In such a

\section{Introduction}

Farming God's Way (FGW) is being widely promoted by churches and faith-based organizations (FBOs) as a development intervention for improving food security, adapting to climate change, and restoring soil productivity for resourcepoor farming households in Sub-Saharan Africa. ${ }^{1}$ FGW is equated with conservation agriculture (CA) but embeds it in a theocentric (God-centered) belief system that invocates God as the First Farmer who doesn't plough, interprets

\footnotetext{
${ }^{1}$ Farming God's Way is also known historically as Conservation Farming (in Zimbabwe) and, more recently, as Foundations For Farming. Farming God's Way (FGW) is used in this paper because it is more commonly used in food security programs, among farmer beneficiaries, and in the literature.
} 
mulch as God's blanket, and mimics biodiversity and other natural processes attributed to the Garden of Eden. ${ }^{2}$ These biblical metaphors correspond to the three agronomic principles of CA: no tillage, mulching, and crop rotation.

However, FGW is more than CA principles re-labelled with religious symbols. It aims to fundamentally re-orient a farmer's mindset - the lens through which they interpret and understand the world, including their relationship to the spiritual, human and non-human realms (God, neighbour, creation). For example, FGW may seek to transform an ancestral or fatalist view of farming (I farm the way my ancestors farmed or I farm because I'm poor) to one that views farming as a spiritual vocation whereby producing food is a way of edifying God and loving one's neighbour, and caring for the soil is an act of ordained sustainability. The aim of FGW is to transform the farmer, and why and how they farm. This transformed mindset then facilitates the adoption and spread of FGW, especially among Christian farmers.

Despite this religious distinction, FGW claims many of the same production, sustainability, and household benefits as CA (Hobbs et al. 2008; Bot 2001; Marongwe et al. 2011; Chan and Fantle-Lepczyk 2015; Farooq and Siddique 2015; Pittelkow et al. 2015). These include higher crop yields, more efficient use of inputs, and improved soil health. Socio-economic benefits include cash from sale of surplus production, reduced labour (less manual tillage), and greater household resilience to climate variability, especially drought. FGW is also generally associated with positive environmental outcomes such as soil erosion control, water conservation, and ecological services (soil carbon sequestration). Based on these success claims, FGW is widely promoted via churches and FBOs through media, agricultural extension, scaling up programs, advocacy campaigns, and agricultural policy formulation (FGW n.d.; Dryden 2009, 2010; Andersson and Giller 2012; Baudron et al. 2012a; Sutherland Smith 2013; Knot et al. 2014; CFGB 2015, 2017; CCK n.d.).

Critical commentaries have questioned the CA claims that FGW has borrowed. For example, yields often decrease in the early transition from conventional tillage-based agriculture to FGW, usually due to increased weed pressure. More weeds may increase peak labour demand, which may offset initial labour savings from no tillage. A shift in labour demand differentiated by gender (tillage by men, weeding by women) may lead to an increased workload for women. CA critics argue that disparate bodies of evidence from field research and on-farm trials in Sub-Saharan Africa challenge the universality of many CA claims, thus also questioning

\footnotetext{
${ }^{2}$ FGW links the Christian faith to agriculture. We acknowledge that other faiths may have their own expressions such as Islamic Farming (Ahmad 2014).
}

the assertions made by FGW (Giller et al. 2009; Baudron et al. 2012b; Andersson and D'Souza 2014; Stevenson et al. 2014; Pittelkow et al. 2015).

The faith basis of FGW is also not without criticism. A key complaint is that faith has supplanted agronomic science as the central theme in the FGW narrative (Andersson and Giller 2012; Baudron et al. 2012a). Disputed scientific evidence in CA should be answered only by more research, not by sanctioning a faith-based approach, according to a rational view of agronomy. Combining faith and agronomy is lamented but substituting or prioritizing faith for agronomy is particularly condemned (see opening quotes).

The FGW narrative is contested from scientific, socioeconomic and religious perspectives. This paper explores this narrative by examining various claims made by FGW from these perspectives. Our research question is: what FGW claims are contested by who and why? Selected biophysical claims (soil moisture, weed control) and socio-economic claims (gender, household resilience) are studied, as well as the intertwining of agronomy and faith. The focus is on claims identified in a qualitative study of program managers of Canadian FBOs that support CA or FGW projects in Africa and FGW farmers in Kenya. Claims from each group are compared with each other, and the CA literature, to ascertain those claims that are accepted or contested among them.

There are many websites, videos, newsletters, training guides, and other popular resources for FGW but its scholarly literature is rare. Its scant criticism, mostly dismissive, is usually in the context of a broader discussion on contested CA (Giller et al. 2009; Andersson and Giller 2012; Baudron et al. 2012a; Andersson and Dsouza 2014). This paper is the first full scholarly review of FGW and critique of its claims, thus filling a gap in the literature. We compile and analyze first-hand accounts from FGW farmers and FBO program managers in an innovative study. These contribute to the broader literature on contested CA by adding another dimension to the debate: faith-based CA.

The paper begins with a brief overview of the origin and distinguishing features of FGW. The contested nature of CA is then reviewed to frame a contested agronomy and faith in FGW. Next, the approach to the study, including the FGW claims to be examined, are described. This is followed by an analysis and discussion of contested claims resulting from the study. A few reflections conclude the paper.

\section{Overview of Farming God's Way}

\section{Origins}

The founding of FGW in 1984 is attributed to Brian Oldreive, a farm manager for Hinton Estate, a large commercial 
farm in northeast Zimbabwe (Dryden 2009, 2010; FGW n.d.). After observing high runoff, severe soil erosion, declining fertility, decreasing yields, and rising input costs, followed by near-bankruptcy, he prayed for God's counsel and implemented FGW practices on 2 ha. Results were so successful that the area under FGW expanded to 3500 ha in 5 years, made possible in part by crop failures and acquisition of bankrupt neighbouring farms who did not adopt FGW. Relying on his commercial success, Oldreive undertook to down-scale FGW for smallholding farmers in Zimbabwe and Zambia with support from national governments and the World Bank (Dryden 2009).

During more than 30 years of set-backs, successes and lessons learned, promotion and adoption of FGW expanded to some 20 countries in Sub-Saharan Africa, and beyond including Cambodia, Cuba, Haiti, Honduras, Mexico and Nepal (Dryden 2009). A concurrent global interest in CA undoubtedly facilitated the spread of FGW, but unique to its expansion is a faith-based network comprised of many denominations, bible schools, mission groups, and FBOs that proliferate across Africa. Although the extent of CA has been estimated at 400,000 smallholders on $1 \mathrm{M}$ ha in Sub-Saharan Africa, with the highest adoptions in eastern and southern Africa (Corbeels et al. 2015), the area under FGW or number of FGW farmers remain largely unknown or at project-level only. For example, Goodwin (2012) reports a training target of 9000 farmers in Zimbabwe in 2010 but the number of farmers that implemented it is not known.

\section{FGW framework and practice}

FGW is not the first to link faith and agriculture in Africa. For example, Gitau (2000) studied how traditional beliefs shaped local understandings of land, rain, plants and animals, and their relationship to subsistence farming and nomadic herding, among the Kikuyu and Masai peoples of Kenya, respectively. He observed that many of their cultural values such as caring for the land and attributing rain as a blessing from the Creator have parallels in the Old Testament Scriptures. A contrasting example is a critique by Baudron et al. (2012a) of "The Gospel of the Plow", a hegemonic colonial policy (1920s) of agricultural intensification on segregated "Native Reserves" in Zimbabwe symbolized by the plow, which was widely promoted by American missionary Emery Alford and mission schools, only to contribute to severe soil erosion and land degradation on the reserves. Ironically, this policy is abandoned decades later under new intensification policies promoting CA without a plow. Theological approaches to integrating faith and agriculture are usually focused on developing first principles based on a particular biblical hermeneutic (interpretation) with applications to land or food policy, sustainable agriculture, food justice, farming practices, among others (Evans et al. 2003;
Fountain 2007; Njoka 2003; Sorley 2009; Spaling 2003). For example, Spaling (2003) proposed a set of principles for agricultural stewardship in Africa that included: (i) a diverse, flourishing agricultural landscape gives praise to the Creator, (ii) enjoy the fruits of creation but do not destroy its fruitfulness, (iii) a Sabbath is for creation too, and (iv) some parts of creation are not for agriculture. FGW follows this theological approach but is distinctive in its African origins, re-casting agronomic principles of CA as faith concepts, prescribing field practices deemed consistent with faithful farming, and using a faith-based network for widespread diffusion and adoption. No other theologically-shaped farming narrative has had such a global reach.

Conceptually, three components make up the FGW framework (Dryden 2009, 2010; FGW n.d.). A biblical component establishes metaphors (God doesn't plow, God's blanket, Garden of Eden) for each CA principle (no tillage, mulching, crop rotation) and reinforces Christian teachings such as acknowledging and relying on God, faithful living, and tithing. Management denotes timely activities (seeding, weeding), high standards (straight rows, spacing, seed density), and minimal wastage (efficient use of inputs, retaining crop residue). Technical refers to prescribed agronomic practices derived from CA, particularly as these mimic natural processes (mulching, composting), but may also include inputs such as improved seed, fertilizer or herbicide. FGW farmers are to follow detailed field specifications regarding layout, spacing, timing, seeding rate, planting depth, micro-dosing (manure, compost, fertilizer), mulching thickness and area, thinning, weeding - all focused on planting stations (a small, permanent planting site about $15 \mathrm{~cm} \times 15 \mathrm{~cm}$ ). The biblical, management and technical components represent a cohesive, integrated whole that are to be practiced together, resulting in many purported benefits of FGW (Table 1). Discarding any one component risks production and unfaithful farming.

\section{FGW contested}

Farming God's Way is contested in several ways. First, scientific debate about the role, priority and universality of CA principles affects FGW similarly. For example, no tillage is frequently considered the priority principle but yields decrease when no tillage is practiced alone (Brouder and Gomez-Macpherson 2014). On the contrary, no-till combined with residue retention and crop rotation generally increases yields, but normally only under rainfed agriculture in drier areas because of improved water infiltration and retention (Stevenson et al. 2014; Pittelkow et al 2015). Climatic variation contests the oft-quoted claim that CA principles " ... are universally applicable in all agricultural landscapes and cropping systems" (FAO 2017, p. 1). Benefits from mulching are also well known (improving water infiltration, suppressing weeds, adding organic matter) but 
Table 1 Claimed benefits of Farming God's Way (Dryden 2010)

\begin{tabular}{|c|c|c|}
\hline General & Soil & Economic \\
\hline Minimal runoff & Improved water holding capacity & Pest and disease control \\
\hline Minimal erosion & Improved fertility & Reduced field preparation cost and time \\
\hline Improved infiltration & Nitrogen fixation-legume rotations & Reduced fertilizer losses \\
\hline Decrease in evaporative loss & Reduced compaction & Improved drought tolerance and risk spread \\
\hline Cooler soil temperature & Improved aeration & Reduced irrigation costs \\
\hline First rain not wasted & Improved soil microbiology & Improved crop efficiency \\
\hline Improved weed control & & Yield improvements \\
\hline
\end{tabular}

biomass is generally less available in drylands, livestock may compete for mulch as fodder, and some root and foliar diseases are associated with mulching (Giller et al. 2009; Corbeels et al. 2015). Crop rotation too may impose constraints. For example, a maize-legume rotation assumes that a farmer with short term food or cash needs will forgo land or a cropping cycle devoted to maize for a legume that may not be a household staple or lack a market.

Additional questions pertain to field practices specific to FGW. For example, its rigid planting system is labour intensive and unlikely to be suitable across all farming systems. Also, unlike CA, FGW only endorses solo-cropping (one crop in a field at one time) and not intercropping (two or more crops in a field at one time) on the assumption that crops compete (Dryden 2009). Although yields for the same crop (maize) are often higher under solo than intercropping, the total yield of two crops (maize and beans) is generally greater than that of a solo crop (Baudron et al. 2012b). Further, nitrogen fertilizer rates prescribed by FGW are equivalent to $378 \mathrm{~kg} / \mathrm{ha}$ (Dryden 2009) compared to a recommended $75 \mathrm{~kg} / \mathrm{ha}$ for maize in the central highlands of Kenya (Kibunja et al. 2017), disregarding FGW's own standards of no wastage and care of creation (risk of water contamination).

Second, the above agronomic criticisms challenge a broader model of sustainable intensification presumed in CA and FGW (Baudron et al. 2012a; Whitfield et al. 2015). This model postulates that both intensified production and resource sustainability (soil health) are achievable. "CA aims to achieve sustainable and profitable agriculture ... It is a way to combine profitable agricultural production with environmental concerns and sustainability" (FAO 2018). A criticism of this model is that inputs (seed, fertilizer, herbicides) are usually intensified for short term production gains while soil and ecological sustainability typically occur incrementally over a longer term. Incremental steps toward resource sustainability are unlikely to drive adoption of FGW where farmers are resource-poor and focused on immediate, tangible benefits (Stevenson et al. 2014; Corbeels et al. 2015). Also, an intensification model may disregard local socio-economic realities such as differential land access, labour constraints, and lack of cash for inputs. These inequities may predispose those farmers that can afford to both intensify inputs and invest in longer term soil health, and restrain those that cannot (Giller et al. 2009). The assumed universality of sustainable intensification is challenged by socio-economic inequities among smallholding farmers.

Third, FGW is contested because it is inextricably faithladen, and churches and FBOs are its promoters and institutional drivers, not researchers or extension agents (Dryden 2009, 2010; Andersson and Giller 2012; Baudron et al. 2012a). FGW is essentially faith-sanctioned CA. Its proponents proclaim FGW as the only way to farm faithfully, which, if practiced, will result in blessings of abundance and soil health. For example, Goodwin's (2012) Master thesis comparing agricultural productivity among Foundations for Farming (aka FGW) farmers and conventional farmers in Zimbabwe, attributed biblical teachings of evangelical Christianity to enhanced productivity among FGW practitioners. This primacy of the biblical component may infer that a contested CA characterized by disparate bodies of scientific evidence is giving way to the declared norms of an evangelical faith expressed in biblical edicts with agriculture themes. FGW is more than agronomic know-how: it is an "evangelizing enterprise" (Baudron et al 2012a) that invokes God, interprets mulch as God's blanket, mimics the Garden of Eden, and equates FGW with faithful farming. This faith approach drives the promotion of FGW despite incongruent agronomic research, questioned technologies, and problems of dis-adoption in CA. At its core, science-based CA focused on sustainable intensification is replaced by faith-based CA aimed at transforming the farmer and their farm.

These objections to the production, sustainability, and faith claims of FGW reflect a broader contested agronomy. Sumberg et al. $(2012,2013)$ attribute such an agronomy to three historic factors: economic liberalization and reform (eliminating subsidies for farm inputs), an environmental movement (pesticides, agro-biodiversity), and a participation agenda in agricultural research (farmer-driven field trials). These factors are contentious and contribute to differing narratives. For example, one view is rooted in a rational, 
technical process of agronomic research and extension services, and another sees agronomy as an interplay of values, power and politics among multiple groups (farmers, researchers, governments, FBOs). Each has its own epistemic community of adherents that contest the other, usually on how agronomic knowledge is produced, validated, communicated, and used (Andersson and Giller 2012; Sumberg et al. 2012, 2013). It is in this contested agronomy that FGW also increasingly finds itself.

\section{Qualitative study}

Exposing the assumptions, interpretations and beliefs that frame and shape a particular narrative such as FGW is important for understanding it. For this, we now turn to our qualitative study. Three questions animate it: (1) What is contested from the perspective of agronomic science? (2) What is contested from the perspective of sustainability (biophysical and socio-economic)? and (3) What is contested from a Christian faith perspective? These questions contribute to our overall research question: What is contested in FGW by who and why?

\section{Approach}

A qualitative approach is employed consisting of 21 semistructured interviews and two focus groups. Phase 1 entailed telephone interviews with six current or former program managers of FBOs based in Canada who have international responsibilities for $\mathrm{CA}$ or FGW programs. The Canadian FBOs represented denominational (Mennonite Central Committee, World Renew), non-denominational (World Vision Canada), and consortia agencies (Canadian Foodgrains Bank). Their program managers typically design, oversee, monitor and evaluate $\mathrm{CA}$ or FGW projects in collaboration with implementing partners, usually other FBOs, in countries such as Kenya. These partnerships may also include donors (Global Affairs Canada) and community-based organizations (Farmers Field Schools). All program managers interviewed for this research had knowledge of and field experience with CA or FGW.

Phase 2 involved in-person interviews in Kenya with 13 farmers ( 9 women, 3 men, 1 couple) practicing FGW, two key informants (FBO staff, Ministry of Agriculture), and two focus groups (15-40 FGW farmers/group). The study area is located in the sub-county of Tigania West, Meru County, situated on the northeastern slopes of Mount Kenya (300 km from Nairobi). Climatic and soil conditions are generally favourable for rainfed (1250-2514 mm/year) agriculture but the area does experience erratic rainfall and periodic drought. Most farmers are engaged in subsistence farming growing food crops such as maize, beans, sorghum and millet.

Anglican Development Services-Mt Kenya East division began a FGW project in 2012 with financial and organizational support from World Renew and Growing Hope Globally, both American FBOs. The project is targeting seven communities and 1000 beneficiaries (FGW farmers and their households). Care of Creation Kenya (CCK n.d.) trained project staff in FGW who, in turn, trained some 280 FGW farmers. Training typically consisted of 8 days of teaching both biblical principles and agronomic techniques of FGW, applying skills learned on practice plots, and observing field demonstrations that compare FGW and conventional farming. Trainees in each community are organized into Farmer Field Schools. These are farmer-driven learning groups that collectively design, implement, monitor, and evaluate various FGW field trials under local conditions. Learnings are then shared among farmers to apply on their own farms. Farmers may receive follow up training or on-farm extension visits from FGW project staff. In the study area, most FGW farmers choose to grow the same staple crops (maize, beans) as they did under conventional farming, but with FGW techniques applied.

The communities of Kiandiu and Kitheo were selected for this research because farmers there are among the first to be trained in FGW. Criteria for selecting farmers for interviews included (1) membership in one of the two FGW Farmer Field Schools, (2) at least one male participant per group (>75\% of FGW participants are women), (3) practicing FGW for 3 or more years, and (4) residing less than $2 \mathrm{~km}$ from a FGW group leader's farm for access and local protocols. Interviews were normally conducted at the household, lasting up to 2 hours, and assisted by a local translator. All interviews were recorded and transcribed, and subsequently coded and analyzed qualitatively using QSR International's NVivo 11 Software (QSR 2015).

\section{FGW claims}

The study is focused on eight claims made by FGW. These broadly represent biophysical and socio-economic changes relative to conventional tillage-based farming practices. The claims are derived from the literature and interviews with FBO program managers, FGW farmers, and key informants. The eight FGW claims examined in this study, and a brief rationale for each, are as follows:

Claim 1 Soil moisture is increased No tillage limits evaporation of soil moisture and mulching improves infiltration, increasing water availability at critical growth stages and for a longer duration, especially in dryland areas and during drought. 
Table 2 Contested or accepted claims made by Farming God's Way

\begin{tabular}{lllll}
\hline FGW Claims & $\begin{array}{l}\text { Program } \\
\text { Managers }\end{array}$ & $\begin{array}{l}\text { FGW } \\
\text { Farm- } \\
\text { ers }\end{array}$ & CA Literature & Why accepted or contested \\
\hline 1. Soil moisture is increased & $\checkmark$ & $\checkmark$ & $\checkmark$ & Consensus for drier zones \\
2. Soil fertility is enhanced & $\checkmark$ & $\checkmark$ & X & Contested by soil type \\
3. Weed control is improved & X & $\checkmark$ & X & Contested during transition to FGW \\
4. Labour demand on women is increased & $\checkmark$ & X & $\checkmark$ & Contested by women farmers \\
5. Adaptation to climate change is enhanced & $\checkmark$ & $\checkmark$ & $\checkmark$ & Consensus for erratic rainfall zones \\
6. Household food security is improved & $\checkmark$ & $\checkmark$ & X & Contested for higher, stable yields \\
7. Adoption factors support FGW & X & $\checkmark$ & X & Contested for varying agro-ecological and socio-economic \\
8. Faith has a positive influence & X & $\checkmark$ & X & Conditions, and faith as a platform \\
\hline
\end{tabular}

$\checkmark=$ claim accepted; $X=$ claim contested

Claim 2 Soil fertility is enhanced Break-down of mulch adds organic matter to the soil and crop rotation using legumes supplies nutrients.

Claim 3 Weed control is improved Weeds are managed by mulching, crop rotation, and timely weeding.

Claim 4 Labour demand on women is increased Where farm labour is differentiated by gender, labour is reduced for men (no tillage) but increased for women (weeding), especially during the transition from conventional farming to FGW.

Claim 5 Adaptation to climate change is enhanced More soil moisture (claim 1) enables the farm to adapt to erratic rainfall and increased frequency and duration of drought.

Claim 6 Household food security is improved Higher yields improve food availability and stability, increasing cash sales and contributing to household resilience against unexpected shocks (drought, disease).

Claim 7 Adoption factors support FGW Farmers are incentivized to adopt FGW not only because of biophysical and socio-economic benefits but also because religious meaning is a catalyst for transforming farming as a vocation and why and how to farm.

Claim 8 Faith is a positive influence Faith can re-orient beliefs, change mindsets, and connect spirituality to livelihood, and provide a networked platform for spreading FGW.

Next, each claim is examined from the viewpoint of farmers, program managers, and the CA literature to ascertain those accepted or contested in the study.

\section{Agronomy and faith contested}

A summary of the main findings is presented in Table 2 . Only two claims, increased soil moisture (\#1) and enhanced adaptation to climate change (\#5), are accepted collectively among program managers, farmers, and the literature. Program managers and farmers additionally agree on enhanced soil fertility (\#2) and improved food security for the household (\#6). The literature contests five claims. Farmers practicing FGW accept all claims except increased labour demand on women (\#4), which female farmers adamantly contested.

\section{Soil moisture}

Farmers, program managers, and the CA literature generally concur that soil moisture is increased under FGW (Table 2, \#1). This is attributed primarily to mulching which reduces runoff, enhances infiltration, and decreases evaporation. Related practices such as planting basins and terracing can further enhance soil moisture reserves. FGW farmers see and feel wetter soil during the growing season and observe a longer time for maize to dry at harvest, compared to conventional farming. They attribute higher yields mainly to more soil moisture, particularly when rainfall is less or erratic. "Even though there are climatic changes, it is not going to affect the harvest as much, because now for example in the part that is not covered, if it rains a little, the water evaporates if the sun comes up. But now for the part that is covered, the coverings help retain the water within the soil and still the crops grow" (Farmer 12).

Program managers and key informants affirm the observations made by farmers (Table 2). "Farmers start to talk about: my soil seems to be absorbing more water, my soil seems to be holding more water and nutrients, my soil looks darker" (Manager 3). Like farmers, they associate higher soil moisture content with mulching. 
The CA literature generally confirms increased soil moisture although this evidence is most consistent in drier zones (Table 2) (Okeyo et al. 2014; Palm et al. 2014; Stevenson et al. 2014). Available moisture may vary by soil type. For example, Thierfelder and Wall (2009) studied the effects of $\mathrm{CA}$ on infiltration rates and soil water content for different soil types in Zambia and Zimbabwe. Infiltration rates increased from 45 to $49 \%$ in CA plots on sandy soils and $57-87 \%$ in CA plots on fine-textured soils, compared to control treatments with conventional tillage. They conclude that CA has the potential to increase rainwater efficiency and reduce the risk of crop failure during moisture stress. Although most studies affirm this conclusion, a few attribute moisture extremes such as high runoff to inadequate mulch or water logging to a thick mulch on clay soils (Giller et al. 2009; Baudron et al. 2012b).

\section{Soil fertility}

Farming God's Way farmers and program managers both confirmed improved soil fertility, but CA research is incongruent (Table 2, \#2). All FGW farmers claimed that retaining crop residue or regularly adding mulch to the field improves soil fertility (organic matter, nutrients). Farmers attributed a visual darkening of the soil, improved tilth, and more macroorganisms (earthworms) to increasing organic matter. Key informants also affirmed better soil fertility: "By covering it with the mulch, and the mulch decaying on that soil and not removing the maize stalks, allowing it to rot there, it is adding a lot of humus to the soil ... this was improving the soil structure, and this was making the soil to be more fertile and we knew that if the soil is fertile it will feed us, and if it is not fertile it will not feed us" (Informant 3).

Program managers also confirmed an increase in soil organic matter (Table 2). Commenting on a field visit with FGW farmers, one manager stated: “... their ability to manage soil moisture and the amount of organic matter that they have built on their soil is an incredible testimony to the practices that come from these (CA) principles, and I find that really impressive" (Manager 1). Program managers associate an increase in soil organic matter with mulching and more available nutrients with crop rotation that includes nitrogen-fixing legumes. They also attribute darker soil colour to improved soil fertility, accepting the farmers' visual indicator.

Increased soil organic matter and nutrient availability is often reported in the CA literature (Hobbs et al. 2008; Twomlow et al. 2009; Luo et al. 2010; Marongwe et al. 2011; Mupangwa et al. 2012; Palm et al. 2014; Dordas 2015). However, consensus is lacking (Table 2). Some researchers point out that soil organic matter is contingent on the availability of organic inputs (crop residue, manure, compost). Competition for fodder may reduce availability of crop residue. Proximity of inputs also affects availability. Fields nearer to the homestead usually have higher organic matter because sources of manure and compost are nearby (Zingore et al 2007; Guto et. al. 2011). Soil type is also an important factor. Organic matter is typically lower in sandy soils because they lack the physical and structural properties that hold and preserve it (Chivenge et al. 2007). Darker soil colour may be deceiving as well. Adding mulch without tillage may increase organic matter content in the upper soil horizons, darkening them but not lower layers (Baudron et al. 2012b; Giller et al. 2015). Tillage incorporates organic inputs deeper into the soil profile. The significance of this is demonstrated in an 8-year field trial in Western Kenya that compared soil properties under reduced tillage and conventional tillage, each with crop residue applied (Okeyo et al. 2016). It found that soil organic carbon and maize yields were higher under conventional tillage that incorporated crop residue into the soil.

\section{Weed control}

All FGW farmers reported greater weed control but this is contested by program managers and the literature (Table 2 , \#3). Farmers confirmed reduced weeding on their FGW plots from the very first season and ongoing weed control thereafter. They attributed reduced weed prevalence to mulching. Weeding is still necessary but is not as labour intensive as for conventional farming. "The number of weeds have reduced, it only comes up one or two here and there, where you can go and hand pick, so there's not much weeds because of the covering" (Farmer 12). Further, FGW farmers state that weeds do not proliferate during the transition from conventional farming to FGW because FGW practices contribute to rigorous weed control from the start. No FGW farmers reported using herbicides.

Program managers confirmed that weeds are suppressed by mulch in the longer term but differ from FGW farmers in recognizing that weed proliferation is likely during the transition to FGW (Table 2). "I think a lot of people start off in the first year without cultivating and without maybe doing even chemical weed control, and so sometimes weeds are a problem in year 1 . On year 2 and 3 they go at it and really mulch well, and have good plant density. I think it declines, becomes less of a problem. But on year 1, I have heard several people say, CA took some extra work because it took me a while to get the weeds under control" (Manager 3 ). An early spike in weeds is likely to increase peak labour demand, especially for women (discussed below), or require a cash expense for hired labour or chemical control. Program managers view weeds as a transition challenge that can be controlled after a few years.

Research data from CA plot and farm trials generally acknowledge an increase in weed intensity during the 
transition phase and a corresponding yield decline (Table 2) (Giller et al. 2009, 2015; Brouder and Gomez-Macpherson 2014; Pittelkow et al. 2015). Since resource-poor farmers usually focus on short-term returns, early weed competition and reduced yield are significant barriers to CA adoption. In response, some researchers advocate herbicide use. For example, a study comparing herbicide use and manual hoeing in zero, minimum and conventional tillage systems with three cropping schemes in Western Kenya found more than $50 \%$ decline in weed abundance and diversity within 1 year under zero and minimum tillage treatments that included herbicides without any reduction in maize yield (Odhiambo et al. 2015). However, the cost of herbicides may be prohibitive for resource-poor farmers, and they may lack training in safe handling and proper application.

\section{Labour and gender}

All program managers and much of the CA literature reported an increased labour demand on women, especially for weeding during the transition to CA. On the contrary, FGW farmers in the study, who are $71 \%$ women, contested this claim and insisted that their labour is reduced immediately and permanently due to less weeding (Table 2, \#4).

Program managers described increased labour demand on women as short term (Table 2). "Potentially, especially in the initial years of practicing CA that leads to more work for women, and less tilling going on, so the men sit around. In the first couple years there is more growing potential for weeds. It is dug by hand or just by crunching, and as tradition, women do this. I would say this is one of the bigger social barriers during the first couple of years on a given farm, with the perception, and in many cases the reality, that it is more work, particularly for women, who are already over worked" (Manager 2). Program managers do acknowledge a decrease in labour for women over the long-term, after weeds are controlled by mulching and crop rotation.

The CA literature generally recognizes a link between $\mathrm{CA}$ and gender-differentiated impacts among smallholding farmers (Giller et al 2009; Whitfield et al. 2015) but comprehensive field studies are limited and findings vary. For example, Nyanga et al. (2012) found that women in Zambia decreased their labour for weeding only when herbicides are used. However, chemical control may disrupt mixed cropping or crop rotation patterns, and eliminate edible weeds consumed by the household, adversely affecting food security and requiring more time on it during the hungry season. Conversely, Maher et al. (2015) found labour for female CA farmers to be consistently less (average of 34 days/year) than that of conventional agriculture in Malawi. CA also redistributed work throughout the year, reducing peak labour requirements. This study also found that more female CA farmers were engaged in supplemental income activities, and households practicing CA benefited from one more month of food availability than those practicing conventional agriculture. Women also adopted CA at faster rates than men.

Gender-related findings from our Kenya study closely parallel those of Maher et al. (2015), countering the results of Nyanga et al. (2012) and claims by program managers (Table 2). FGW farmers (female and male) indicated that women do not have a greater labour load than men on the farm. They insisted that weeds decreased in the transition to FGW due to mulching, and that reduced labour from less weeding is immediate, permanent and available for other household or livelihood activities.

In most FGW households in the study, farm work is not gender-assigned but shared equally. Greater gender equality is also attributed to faith. "For those who are familiar with God, what they plan, they do together, like me and my husband" (Farmer 1). Gender equity is emphasized in many churches and FBOs, and practiced in FGW programs by providing equal access to training, recruiting female trainers, and encouraging female leaders of farmer groups. In the few households where FGW tasks are gender differentiated, both genders may benefit from reduced labour in their gendered tasks-no tillage by men and less weeding by women.

Despite a reduced burden on women overall, labour demand still may peak during time-sensitive activities such as planting and harvesting, or increase with farm size, necessitating hired labour. All but two FGW farmers reported hiring workers for some farm activities but the time and cost of hired labour is less than that of conventional farming. "My labour has reduced, I do not do as much work on the farm as I used to do before, even the cost has reduced because I no longer have to pay people to till the farm and also do the weeding, so that money is channeled into another project within the home" (Farmer 14). However, femaleheaded households may remain particularly disadvantaged, as revealed in one interview. The interviewee, recently widowed, explained that land inheritance along male lines left her with only a small plot of land. She practiced FGW on this plot and benefited from increased production but the inherited plot was too small for all of her family's needs. Despite some progress toward gender equality as demonstrated by other female FGW farmers, female-headed households may face ongoing challenges of land tenure, access, and inheritance (Aboud et al. 1996; Burke et al. 2018).

Overall, farmers contest claims of increased weed density during the transition to FGW resulting in an increased labour demand on women. Instead, reduced labour from the start, along with opportunities for training, new knowledge and skills, shared learning, and social support, motivate women to adopt FGW, contributing to gender equality and empowerment, and diminishing the gender gap in farming (Maher et al. 2015). 


\section{Climate change adaptation}

The Kenyan farmer dependent on rainfed agriculture must adapt to increasingly erratic rainfall patterns characterized by intense deficit (drought) or surplus (floods) and unpredictable distribution (onset, timing). FGW farmers, program managers, and the literature advocate $\mathrm{CA}$ for its climate change adaptation (Table 2, \#5). For this reason, CA is often equated with Climate Smart Agriculture. However, the role of CA in climate change mitigation such as through soil carbon sequestration is contested.

All FGW farmers confirmed that their farms are more resilient to increasingly erratic rainfall. They state that even when the rains are below average, they will still obtain some harvest to feed their family. "My family has been getting [harvest] throughout, since I started practicing [FGW], even when the rains are not enough. The other [conventional] part; there is nothing to harvest. Before, if the rains were not enough, there was nothing to harvest. But now, even though it rains very little, the part where I am practicing FGW, I am able to get some food to take care of my family" (Farmer 12). Other FGW farmers compared their farms to their neighbours' farms, where conventional farming is practiced, and affirmed how much more successful their FGW fields are during reduced or poorly distributed rainfall. These farmers reported some harvest, even with only one or two rains in the season, while their neighbours experienced crop failure.

Program managers concur that CA can support the smallholder in adapting to climate change (Table 2). "I realized that conservation agriculture in the sense of the three principles that it embodies: continuous cover of the soil, minimal or no tillage, crop rotation or inter cropping, those seem to me to be ideal practices in terms of mitigating vulnerability to variations in climate, from season to season, on either extreme, either shortages of rainfall or excess of rainfall" (Manager 5). Key informants similarly explained that increased soil moisture because of mulching is critical to mitigating the effects of erratic rainfall. "Also with the issue of climate change, CA to me is an answer. If you plant and if it rains even twice it will be enough to sustain the crops, if the crop is well covered and the farmer will get something as compared to a farmer who does not cover the land" (Informant 3). FGW provides a buffer against complete crop failure when rainfall is reduced or poorly distributed. Buffering is important for strengthening household resilience to climatic extremes (Speranza 2013).

Much of the literature affirms CA as an effective response to climate change for the smallholder (Table 2) (Hobbs et al. 2008; Marongwe et al. 2011; Kaczan et al. 2013; Schaller et al. 2017; Thierfelder and Wall 2010; Thierfelder et al. 2017). Speranza's (2013) survey of 41 CA farmers in the Laikepia region of Kenya provides a direct account of farmers' experience with changing climate and the buffering capacity of CA. Farmers interpreted climate change as altered and unpredictable rainfall patterns (76\%), reduced rainfall (54\%), prolonged drought (20\%), and interchanged rainy seasons $(15 \%)$. CA practices that improved soil moisture on the farm include mulching (59\%), ripping $(20 \%),{ }^{3}$ and digging trenches and furrows (15\%). CA farmers reported that soils retain more water $(37 \%)$, harvests are secured during dry spells (29\%), and trees and plants survive dry spells (24\%), among other benefits (Speranza 2013). These practices are representative of CA's potential for climate change adaptation, which explain its link to Climate Smart Agriculture (Kaczan et al. 2013; Speranza 2013; Schaller et al. 2017).

However, CA is not a panacea for climate change. Its role in climate mitigation is uncertain, particularly a claim that $\mathrm{CA}$ acts as a carbon sink by sequestering atmospheric carbon dioxide into the soil. A policy corollary is that CA farmers should be compensated for their contribution to mitigating global climate change. However, empirical evidence comparing soil carbon sequestration in CA and conventional agriculture is often contradictory and inconclusive (Henry et al. 2009; Andersson and Giller 2012; Palm et al. 2014; Okeyo et al. 2016). Powlson et al. (2016) conducted a meta-analysis of 47 studies of CA and soil organic carbon in Sub-Saharan Africa and found that most studies reporting increased soil organic carbon are overestimates because of errors in soil sampling methodology. Further research is necessary before proposing payments for carbon sequestration as part of an incentivized CA package.

Overall, FGW farmers, program managers, and the CA literature accept the claim that CA enhances adaptation to climate change because practices such as mulching maintain soil moisture content above critical thresholds for crop growth under increasingly erratic climatic regimes. Evidence for soil carbon sequestration and a role of CA in mitigating global climate change is contentious and requires more research.

\section{Household food security}

Food security is understood here in terms of four pillars endorsed by the Food and Agriculture Organization (FAO 2008): availability (supply of food), access (affordability of preferred food), utilization (safe, nutritious food), and stability (ability to obtain food over time). Achieving all four pillars concurrently is necessary for a food secure household. Food security in the study area is characterized by food availability during post-harvest periods from January

\footnotetext{
${ }_{3}$ Opening the soil such as for a seed row or capturing runoff but not turning it over.
} 
to February and again from June to August. Households are most prone to food insecurity from October to December due to a prolonged dry spell. A comprehensive survey of multiple factors affecting food security in the study area is beyond the scope of this paper. Instead, crop yield is used as a basic indicator, particularly of food availability and stability. In general, program managers and farmers concur that FGW increased yields and thus improved food security for the household although this is not without some challenges. Findings in the CA literature are more diverse (Table 2, \#6).

Farmers practicing FGW unanimously affirmed increased yields - by at least double according to one farmer (Farmer 10). This gives FGW households enough to feed the family through the dry season, while others continue to experience a "hungry season". Sale of some surplus yield and decreased expenses (hired labour) provide more cash for other household needs such as purchasing livestock, paying school fees, or improving farm infrastructure (grain storage, livestock sheds). All farmers associated FGW with long-term food security for the household, and reported that their farms will benefit food security of future generations because of enhanced soil fertility.

The farmers also identified some limitations to household food security under FGW. First, households are food secure only if they own one acre ( 0.41 ha) or more. Smaller farms will see increased yields but not enough to become fully food secure. Second, although FGW improves food security, notably food availability and stability, it is not sufficient to satisfy all immediate and multiple household needs (education, health, funerals, cultural feasts, transport). Saving funds for the purchase of next season's certified seed, fertilizer or hired labour also can be a challenge, and not purchasing them is to risk yield decline. Third, in addition to competition for mulch as fodder for cattle, farmers reported a different threat by small livestock. Chickens, searching for termites, scratch away the mulch leaving the seedbed exposed to heat and evaporation, thereby hindering germination. Fencing is one option but costly. Cooperation from neighbours in keeping chickens confined until germination is preferred.

All program managers confirmed higher yields and attributed these to CA principles (Table 2). Food security is improved in terms of both food supply (availability) and its duration (stability). As a result, the length of the annual "hungry season" is reduced or eliminated. "Because we work in communities which are not able to bridge the hunger gap with food, we were able to clearly articulate that previously the food could only last 3 or 4 months. Now they are able to last the whole period which is 7 to 8 months. So they could actually bridge from one rainy season to the next rainy season with the harvests from the last season" (Manager 4). FBOs frequently target seasonal food shortages by emphasizing availability and stability in their food security programs.
The CA literature broadly recognizes a positive correlation between CA and yield, particularly in drier regions (Table 2) (Hobbs et al. 2008; Brouder and Gomez-Macpherson 2014; Stevenson et al. 2014; Pittelkow et al. 2015; Steward et al. 2018). In these areas, land preparation before the first rains facilitates earlier planting and more efficient use of rainfall, reducing the risk of complete crop failure during drought or stabilizing yields when rains are poorly distributed (Baudron et al. 2012b; Speranza 2013; Giller et al. 2015). For example, CA farmers in Zimbabwe attributed yield increases to timely planting, better soil moisture, and availability and precision placement of fertilizer (Marongwe et al. 2011). These practices improved food security during normal climatic conditions and helped to stabilize it during erratic rainfall.

Despite near-consensus on CA and yield in drier areas, occasional studies show contrary results. For instance, onfarm trials in the semi-arid Zambezi Valley of Zimbabwe comparing cotton and sorghum yields for 3 years under CA and conventional practices found that $\mathrm{CA}$ did not increase yields during years of average and above-average rainfall, and decreased yields during a below-average year (Baudron et al. 2012b). Researchers found no beneficial or detrimental effect of CA compared with conventional practices, concluding that good farm management such as adequate fertilization, timely planting and weeding, and pesticide application is more important than factors that differentiate CA and conventional practices.

Although site-specific studies result in occasional contrary findings on CA yield, farmers and program managers in this study fully support the claim that yield and household food security are enhanced by FGW.

\section{Adoption of FGW}

Why do farmers adopt or not adopt FGW? Their explanations do not fully align with those of program managers and the CA literature (Table 2, \#7).

Various reasons for, and barriers to, adoption of CA are postulated elsewhere (Knowler and Bradshaw 2007; Giller et al. 2009; Kinyumu 2012; Arslan et al. 2014; Andersson and D'Souza 2014; Corbeels et al. 2014; Odhiambo et al. 2015; Whitfield et al. 2015; Van Hulst and Posthumus 2016). Key prerequisites for adoption seemingly include changing mindsets, acquiring knowledge and skills, adapting to local agro-ecological and socio-economic realities, and socialization with other adopters for shared learning. These aspects pertaining to the study are briefly considered here.

Changing mindsets is part of the CA adoption narrative, but this narrative accentuates the instrumental-a new way of farming focused on intensification, surplus production, entrepreneurship, market linkages, and resource sustainability (Andersson and D'Souza 2014; Whitfield et al. 
2015). These are also aspects of FGW but secondary to its core narrative. Changing mindsets in FGW is interpreted as a religious motivation centered on faithfulness. "When now we came to a new way of farming, we were taught that God wanted us to farm in the best way and to take care of the soil" (Farmer 1). A FGW farmer is asked to restore their relationship to God, people and creation, and to express this renewed relationship in their livelihood. Unlike the external motives assumed in the CA adoption narrative, the FGW narrative appeals to deeply held internal convictions to farm faithfully. This distinction is not without limitation, however. A key informant viewed FGW as a potential barrier to adoption as "you cannot address them all using the same religious approach" (Informant 2), referring to the unlikelihood of someone adopting FGW who does not identify as Christian.

Adapting to local agro-ecological conditions and socioeconomic realities is a repeated theme in the CA adoption literature (Giller et al. 2009; Andersson and Giller 2012; Baudron et al. 2012a, b; Corbeels et al. 2015). Program managers concur, stating that the key to success in CA is "teaching it and presenting it in such a way that farmers understand the principles behind it and can innovate and adapt the system to their context" (Manager 1). CA is viewed as an endeavor that takes time to try out, learn from, and steadily improve. However, program managers are critical of the prescriptive agronomic requirements of FGW, which they see as hindering adaption to site-specific contexts. They also expressed concern that farmers may interpret FGW as a divine instruction not to be tampered with, stifling on-farm innovation. "It's difficult because the problem with equating Farming God's Way with God's way of farming is that than it must be perfect ... therefore why would you need to innovate and adapt?" (Manager 6). For these reasons, most program managers of Canadian FBOs no longer promote FGW in their food security programming (discussed below).

Adopting FGW requires that the type and number of farming practices must be changed at the same time. FGW farmers acknowledge that gaining the knowledge and skills necessary for practicing FGW, and its perceived labour requirement, may dissuade adoption. "One of the reasons why they just stop is because this type of farming requires a lot of time and attention. On the other side, they are used to just come, till and go, no digging, no measuring, not much work. So that makes them feel this is too much, and they don't have the patience for it, especially in collecting the leaves. So those are some of the things that discourage them from continuing" (Farmer 9). Learning and practicing myriad agronomic details and management behaviours, plus biblical teachings, may be a barrier for some.

CA adopters may face strong social pressure to return to traditional ways of farming. Program managers emphasized the importance of the learning process and socialization in adopting CA long term. "It (CA) is sustainable not because of the technology itself, but more because of how it is socialized into the community and how this process of facilitation for the community and the farmers involved is done" (Manager 4). Groups such as Farmer Field Schools play this role for $\mathrm{CA}$, and churches and FBOs do so for FGW.

\section{Faith}

Faith fundamentally transforms a farmer's understanding of their vocation, and why and how to farm. However, the role and importance of faith is contested by program managers and the literature (Table 2,\#8).

Farmers view faith not only as an internal belief system that is privately held, but as an integrating framework for transforming their vocation and livelihood.

"We never took farming as if it were God's desire, or in the way God desired it done. But now we have learned how God since the beginning, in the Garden of Eden, there is a way that God desired that we farm. Compared to the Garden of Eden, and how God has instructed, how we did farming before, we had lost our way, our connection... in FGW, now that we have learned how God expects us to farm, we have learned that God wants us to take care of the soil and take care of the environment. If it was possible for everyone in the community to practice FGW it would be very important as it would help us in conserving the environment and in taking care of the soil" (Farmer 1).

The theocentric framework of FGW connects internal faith convictions to daily farming realities, providing vocational purpose and meaning.

Key informants also recognized that, unlike CA, faith is an important catalyst for changing mindsets and embracing FGW. "CA does not address the issue of relationship between man and God. It is not there, and therefore it does not aim at changing the individual attitude, the heart and the mind are not changed" (Informant 3). Faith shapes a farmer's self-identify and outlook, which influences why and how they farm.

The church and faith-based networks are important platforms for the spread of FGW. In the study, farmers acknowledged the role of Anglican Development Services (ADS) in this regard: "We were trained the (conventional) agricultural way of farming, and then (the trainer) with the ADS came and trained us FGW and explained to us that this is how God wants us to farm. He wants us to take care of his soil, he does not want his soil to be washed away. So that is how, because of our belief in God, we were able to now have the confidence to go and do it, knowing we are doing it for God" (Farmer 9). ADS operates the only FWG project in the study area but other churches often facilitate it. "Before the planting season comes, she is given an opportunity even in church to be able to teach people how to do Farming God's Way, 
so they can go and practice before the rains come" (Farmer 4). "[She] is given an opportunity to share with them in the church, and through that many people have joined the group" (Farmer 13). As a trusted institution in many rural Kenyan communities, the church legitimizes FGW, offering farmers encouragement and confidence in the face of change and risk, and a community of adherents for forming FGW groups, sharing experiences, and learning together.

Program managers also recognized a role for the church in teaching FGW principles and practices, advocacy by pastors, hosting training sessions, and providing church land for demonstration plots. Surprisingly however, five of the six program managers indicated that their Canadian FBO no longer supported FGW in their food security programs. This is attributed, in part, to a criticism that the universal claims and prescribed practices of FGW ignore local context, but faith is also implicated. FGW reflects a specific interpretation of faith that may not be shared across all Christian traditions. Declaring that FGW represents the only faithful way to farm is indicative of a particular evangelical tradition characterized by literal interpretation of the Bible. For example, in the creation story God is anthropomorphic as the First Farmer but the plough, a human invention, is distinctly absent from the Garden of Eden, thus God does not plough and neither should humans. Such literal interpretation is determined to be God's way, establishing human norms for faithful farming. Deviating from these norms, such as tilling the soil or adapting to local conditions, risks being unfaithful. "For me, the challenge with the Farming God's Way biblical principles is they are developed by a very specific faith base ... a very specific brand, or branch of Christianity. And it was a very evangelical, conservative brand, which kind of filters the principles" (Manager 6). Unease, if not disagreement, with literalist approaches contributed to Canadian FBOs withdrawing their support for FGW, but not CA. Another faith-related reason is that FGW is directed at Christian farmers and a policy of most FBOs is not to discriminate program beneficiaries on the basis of religion.

The scant literature on FGW is very critical of a faithsanctioned CA (see opening quotes) (Giller et al. 2009; Andersson and Giller 2012; Baudron et al. 2012a). Critics question the spread of FGW in light of a contested CA characterized by disparate bodies of empirical evidence from research plots and on-farm trails, and an unresolved tension between universal CA principles and local agro-ecological and socio-economic realities. They argue that a contested CA can be best resolved by more agronomic research based on science and rationality. Their main objection to FGW is a theocentric belief system competing with scientific agronomy as the driving narrative. This objection reflects a historical dichotomy between religion and science that is still contested in Western thought (Livingstone et al. 1999; Gregory 2012). While acknowledging a great diversity of cultures and traditional religions throughout Africa, African worldviews generally tend to be more holistic and multidimensional, recognizing fluid boundaries and dynamic interchanges between the physical and spiritual realms (Mbiti 1969; Horton 1993). "In this world, whatever we do, it is as a result of faith. I believe that there is God, and whatever we do, we do it out of our faith in God. That is why I also desired to practice FGW, because I believe in God and I believe there is a way that God wants things to be done" (Farmer 10). This quote seems to suggest that an indigenous worldview characterized by interconnection of the spiritual and physical realms is an influential framework through which faith and agriculture are easily integrated.

Religion, Christian or otherwise, is a powerful force for understanding reality, including farming, in many rural communities. Faith can change mindsets and facilitate adoption of farming approaches deemed to be consistent with that faith.

\section{Conclusion}

This paper has explored how various production, sustainability, and religious claims are contested among FBO program managers in Canada, FGW farmers in Kenya, and the CA literature. Our study found that FGW claims of increased soil moisture and enhanced adaptation to climate change are unanimously confirmed. A claim of increased labour demand on women by program managers and the literature is strongly contested by FGW farmers, especially women farmers. Other claims of improved soil fertility, better weed control, enhanced food security for the household, support for FGW adoption, and faith having a generally positive influence are all confirmed by FGW farmers but contested by program managers or the literature or both. These findings are among the first scholarly research on FGW, helping fill a gap in the literature.

A finding that many production and sustainability claims of FGW are contested is perhaps not unexpected. Incongruent empirical evidence in the CA literature, based on numerous $\mathrm{CA}$ research plots and on-farm trials under various agro-climatic and socio-economic conditions, is likely to contradict some production claims by FGW farmers in this study due to local factors. For example, claims of household food security (higher crop yield) may be attributable to higher average rainfall (1250-2514 mm/year) in the study area, which may also increase biomass available for mulch. An emphasis on management in FGW and farmers meticulously applying its prescribed field techniques may also help explain higher yields and improved food security. Similarly, reduced labour for women, notably for weeding, may be due to the weeding protocols of FGW but likely also integration of gender equity into the FBO's program. Effective training 
in FGW and active extension and social support by the implementing FBO are also important factors in this study. A methodological limitation is that only FGW farmers, all Christians, were interviewed. Farmers practicing conventional farming or those of other faiths were not interviewed, precluding a comparative approach, thus barring voices that may have been more critical of FGW. Other possible limitations relate to common challenges in cross-cultural research such as language translation, location and access, and gender barriers (few men in this study).

A demonstrated contribution of this paper is that discourse on faith is an important and animating element of contested CA, and contested agronomy broadly. FGW and CA share agronomic principles and practices on the farm but their norms, aims, and motives differ fundamentally. Prevailing contested narratives of CA (Whitefield et al. 2015) are not differentiated by religious suppositions even though FGW, a form of faith-sanctioned CA, has been welcomed widely by faith communities across Sub-Saharan Africa for more than three decades. An extensive faith-based network offers a distinct platform for promoting and adopting FGW across the continent. The church is often the only or main institution in African rural communities and a key conduit for connecting regional, national and international expertise, training, and funding to smallholding farmers. Beyond transferring knowledge and skills, a unique contribution of a faith-based network is its capacity for changing mindsets, transforming a farmer's vocational identity including why and how to farm, and connecting deeply held faith convictions with the daily life of farming.

A faith-sanctioned CA is firmly contested by a paradigm of agronomy rooted in objectivity, rationality, and empiricism. However, FGW is not only contested or disapproved by those that do not subscribe to its faith claims. It is also contested by faith adherents (FBO program managers) that are critical of literal interpretations of the creation story becoming the sole norms for faithful farming, and of limitations that faith may impose on adapting FGW practices on each farm. Just as CA is contested from within, so is FGW.

Findings from our study area are unlikely to be representative of all FGW farmers across Sub-Saharan Africa, suggesting opportunities for further research. Future studies should further differentiate and compare FGW, CA and conventional farming approaches with a view to helping resolve a tension between the universality of many production, sustainability and faith claims, and their association with a particular type of farming under local agro-climatic, socio-economic and religious realities. There is also a need for detailed historical-ethnographic research, such as comprehensive case studies, to contextualize and understand the driving forces (e.g., indigenous beliefs and values pertaining to food and farming, colonial and neo-colonial agricultural policies and legacies) that continue to shape, and contest, why and how FGW is practiced in Sub-Saharan Africa. A related research need is for a better understanding of the role of Christianity generally, and evangelicalism specifically, in contributing to changed mindsets and vocation, as well as research on how churches and FBOs promote FGW through a global faith network for insight into its adoption, extent, and similarities and differences among locales.

A contested agronomy and contested faith gives rise to a challenge. A faith-based movement that believes in biblical metaphors for farming derived from one founder's spiritual experience is not an accepted hallmark of agronomic science, and is bound to be contested and opposed by those that believe in the rationality and empirical evidence of agronomy. FGW that is not informed by a scientific agronomy derived from plot trials, applied research, and farmer-led investigations is irresponsible, even from a faith perspective. Likewise, agronomists must accept that cultural realities for the smallholding farmer in Sub-Saharan Africa include a religious dimension that, when appealed to, is a powerful driver for changing mindsets, transforming why and how to farm, and motivating farmers to grow more food, care for the land, adapt to climate change-to farm faithfully. The challenge is for CA and FGW farmers, program managers, agronomists, researchers, and faith-based and other networks to recognize the mutual importance of agronomy and faith.

Acknowledgements We acknowledge the contributions of research assistants Erin Greidanus, Justin Wagenaar, Rehema Mukiri and James Ireri, and host partners Catherine Mwangi, Peter Maina and Stephan Lutz. We especially thank the program managers, key informants and farmers interviewed for this research. Two reviewers also provided helpful comments on this paper. Financial support for this research was received from the Social Sciences and Humanities Research Council of Canada (grant \#435-2016-0108).

Open Access This article is distributed under the terms of the Creative Commons Attribution 4.0 International License (http://creativeco mmons.org/licenses/by/4.0/), which permits unrestricted use, distribution, and reproduction in any medium, provided you give appropriate credit to the original author(s) and the source, provide a link to the Creative Commons license, and indicate if changes were made.

\section{References}

Aboud, A., A. J. Sofranko, and S. Ndiaye. 1996. The effect of gender on adoption of conservation practices by heads of farm households in Kenya. Society and Natural Resources 9: 447-463.

Ahmad, H. 2014. Islamic farming: a toolkit for conservation agriculture. Alliance of religions and conservation. http://www.arcworld. org/projects.asp?projectID=634. Accessed 4 Sept 2018.

Andersson, J. A., and S. D'Souza. 2014. From adoption claims to understanding farmers and contexts: A literature review of conservation agriculture (CA) adoption among smallholder farmers in southern Africa. Agriculture, Ecosystems and Environment 197: 116-132. 
Andersson, J. A., and K. Giller. 2012. On heretics and God's blanket salesmen: Contested claims for conservation agriculture and the politics of its promotion in African smallholder farming. In Contested agronomy: agricultural research in a changing world, eds. J. Sumburg, and J. Thompson, 22-46. London: Routledge.

Arslan, A., N. McCarthy, L. Lipper, S. Asfaw, and A. Cattaneo. 2014. Adoption and intensity of adoption of conservation farming practices in Zambia. Agriculture, Ecosystems and Environment 187: 72-86.

Baudron, F., J. A. Andersson, M. Corbeels, and K. E. Giller. 2012a. Failing to yield? Ploughs, conservation agriculture and the problem of agricultural intensification: An example from the Zambezi Valley, Zimbabwe. Journal of Development Studies 48: 393-412.

Baudron, F., P. Tittonell, M. Corbeels, P. Letourmy, and K. E. Giller. 2012b. Comparative performance of conservation agriculture and current smallholder farming practices in semi-arid Zimbabwe. Field Crops Research 132: 117-128.

Bot, A. 2001. Conservation agriculture: case studies from Latin America and Africa. Rome: Food and Agriculture Organization.

Brouder, S. M., and H. Gomez-Macpherson. 2014. The impact of conservation agriculture on smallholder agricultural yields: a scoping review of the evidence. Agriculture, Ecosystems and Environment 187: 11-32.

Burke, W., S. Li, and D. Banda. 2018. Female access to fertile land and other inputs in Zambia: why women get lower yields. Agriculture and Human Values 35: 761-775.

CCK (Care of Creation Kenya). n.d. http://kenya.careofcreation.net/ what-we-do/farming-gods-way/ Accessed 5 Sept 2018.

CFGB (Canadian Foodgrains Bank). 2015. Conservation agriculture newsletter. vol 1: No. 1. https://www.foodgrainsbank.ca/ wp-content/uploads/2015/12/ca_newsletter-may.pdf Accessed 5 Sept 2018.

CFGB (Canadian Foodgrains Bank). 2017. Preaching the conservation agriculture "Gospel" https://foodgrainsbank.ca/news/preac hing-the-conservation-agriculture-gospel/ Accessed 5 Sept 2018.

Chan, C., and J. Fantle-Lepczyk. 2015. Conservation agriculture in subsistence farming: case studies from South Asia and beyond. Wallingford: CAB International.

Chivenge, P., H. K. Murwira, K. Giller, and J. Six. 2007. Long-term impact of reduced tillage and residue management on soil carbon stabilization: implications for conservation agriculture on contrasting soils. Soil and Tillage Research 94: 328-337.

Corbeels, M., J. de Graaff, T. H. Ndah, E. Penot, F. Baudron, K. Naudin, N. Andrieu, G. Chirat, J. Schuler, I. Nyagumbo, L. Rusinamhodzi, K. Traore, H. D. Mzoba, and I. S. Adolwa. 2014. Understanding the impact and adoption of conservation agriculture in Africa: a multi-scale analysis. Agriculture, Ecosystems and Environment 187: 155-170.

Corbeels, M., C. Thierfelder, and L. Rusinmhodzi. 2015. Conservation agriculture in Sub-Saharan Africa. In Conservation agriculture, eds. M. Farooq, and K. H. M. Siddique, 443-476. Cham: Springer.

Dordas, C. 2015. Nutrient management perspectives in conservation agriculture. In Conservation agriculture, eds. M. Farooq, and K. H. M. Siddique, 79-107. Cham: Springer.

Dryden, G. 2009. Farming God's Way: trainer's reference guide (First Edition). http://www.farming-gods-way.org. Accessed 4 Sept 2018.

Dryden, G. 2010. Farming God's Way: field guide. http://www.farmi ng-gods-way.org/Resources/FGW_Field_Guide.pdf Accessed 4 Sept 2018.

Evans, D., R. Vos, and K. Wright, eds. 2003. Biblical holism and agriculture: cultivating our roots. Pasadena: William Carey.

FAO (Food and Agriculture Organization). 2008. An introduction to the basic concepts of food security (pamphlet). Rome: FAO.

FAO (Food and Agriculture Organization). 2017. Conservation agriculture (pamphlet). Rome: FAO.
FAO (Food and Agriculture Organization). 2018. Sustainable land management tools-conservation agriculture. http://www.fao. org/soils-portal/soil-management/other-slm-tools/en/ Accessed 23 Jan 2019.

Farooq, M., and K. H. M. Siddique, eds. 2015. Conservation agriculture. Cham: Springer.

FGW (Farming God's Way). n.d. http://www.farming-gods-way.org/ home.htm Accessed 5 Sept 2018.

Fountain, Dan, ed. 2007. Let's restore our land. North Fort Myers: ECHO.

Giller, K., E. Witter, M. Corbeels, and P. A. Tittonell. 2009. Conservation agriculture and smallholder farming in Africa: the heretics' view. Field Crops Research 114: 23-34.

Giller, K., J. A. Andersson, M. Corbeels, J. Kirkegaard, D. Mortensen, and B. Vanlauwe. 2015. Beyond conservation agriculture. Frontiers in Plant Science 6: 870: 1-14.

Gitau, S. K. 2000. The environmental crisis: a challenge for African christianity. Nairobi: Acton.

Goodwin, R. F. 2012. The role of faith-based development in enhancing agricultural productivity and responding to poverty: a case study of 'Foundations for Farming' in Zimbabwe. Masters Thesis, Department of Geography. Otago, New Zealand: University of Otago.

Gregory, B. S. 2012. The unintended reformation: how a religious revolution secularized society. Cambridge: Belknap.

Guto, S. N., P. Pypers, B. Vanlauwe, N. De Ridder, and K. E. Giller. 2011. Socio-ecological niches for minimum tillage and cropresidue retention in continuous maize cropping systems in smallholder farms of Central Kenya. Agronomy Journal 104: 188-198.

Henry, M., P. Tittonell, R. J. Manlay, M. Bernouxa, A. Albrecht, and B. Vanlauwe. 2009. Biodiversity, carbon stocks and sequestration potential in aboveground biomass in smallholder farming systems of Western Kenya. Agriculture, Ecosystems and Environment 129: 238-252.

Hobbs, P. R., K. Sayre, and R. K. Gupta. 2008. The role of conservation agriculture in sustainable agriculture. Philosophical Transactions of The Royal Biological Sciences 363: 543-555.

Horton, R. 1993. Patterns of thought in Africa and the West: essays on magic, religion and science. Cambridge: Cambridge University Press.

Kaczan, D., A. Arslan, and L. Lipper. 2013. Climate-smart agriculture? a review of current practice of agroforestry and conservation agriculture in Malawi and Zambia. ESA Working Paper No. 13-07, Rome: FAO.

Kibunja, C. N., K. W. Ndungu-Magiroi, D. K. Wamae, T. J. Mwangi, L. Nafuma, M. N. Koech, J. Ademba, and E. M. Kitonyo. 2017. Optimizing fertilizer use within the context of integrated soil fertility management in Kenya. In Fertilizer use optimization in SubSaharan Africa, eds. C. Wortmann, and K. Sones, 82-99. Nairobi: CAB International.

Kinyumu, D. M. 2012. Is conservation agriculture a solution to dry land rain-fed farming? Experiences and perceptions of smallholder farmers in Laikipia District, Kenya. Journal of Developments in Sustainable Agriculture 7: 134-147.

Knot, J., M. P. De Wit., J. N. Blignaut, S. Midgley, D. J. Crookes, S. Drimie, and N. P. Nkambule. 2014. Sustainable farming as a viable option for enhanced food and nutritional security and a sustainable productive resource base. Field report. Prepared for the Green Fund, Development Bank Southern Africa. Pretoria: ASSET Research.

Knowler, D., and B. Bradshaw. 2007. Farmers' adoption of conservation agriculture: a review and synthesis of recent research. Food Policy 32: 25-48.

Livingstone, D. N., D. G. Hart, and A. M. Knoll, eds. 1999. Evangelicals and science in historical perspective. New York: Oxford University Press. 
Luo, Z., E. Wang, and O. J. Sun. 2010. Can no-tillage stimulate carbon sequestration in agricultural soils? A meta-analysis of paired experiments. Agriculture, Ecosystems and Environment 139: 224-231.

Maher, J., P. Wagstaff, and J. O'Brien. 2015. Empowering women through conservation agriculture: rhetoric or reality? Evidence from Malawi. In Conservation agriculture in subsistence farming: Case studies from South Asia and beyond, C. Chan, eds. and J, 226-238. Wallingford: CAB International: Fantle-Lepczyk.

Marongwe, L., K. Kwazira, M. Jenrich, C. Thierfelder, A. Kassom, and T. Friedrich. 2011. An African success: the case of conservation agriculture in Zimbabwe. International Journal of Agricultural Sustainability 9: 153-161.

Mbiti, J. 1969. African religions and philosophy. London: Heinemann Educational Books.

Mupangwa, W., S. Twomlow, and S. Walker. 2012. Reduced tillage, mulching and rotational effects on maize (Zea mays L.), cowpea (Vigna unguiculata (Walp) L.) and sorghum (Sorghum bicolor L. (Moench)) yields under semi-arid conditions. Field Crops Research 132: 139-148.

Njoka, J. T. 2003. The worship of God through agriculture. In Biblical holism and agriculture: cultivating our roots, eds. D. Evans, R. Vos, and K. Wright, 19-40. Pasadena: William Carey.

Nyanga, H., F. H. Johnsen, and T. H. Kalinda. 2012. Gendered impacts of conservation agriculture and paradox of herbicide use among smallholder farmers. International Journal of Technology and Development Studies 3: 1-24.

Odhiambo, J. A., U. Norton, D. Ashilenje, E. C. Omondi, and J. B. Norton. 2015. Weed dynamics during transition to conservation agriculture in Western Kenya maize production. PLoS ONE. https ://doi.org/10.1371/journal.pone.0133976

Okeyo, A. L., M. Mucheru-Muna, J. Mugwe, F. K. Ngetich, D. Mugendi, J. Diels, and C. Shisanya. 2014. Effects of selected soil and water conservation technologies on nutrient losses and maize yields in the central highlands of Kenya. Agricultural Water Management 137: 52-58.

Okeyo, J., J. B. Norton, S. Koala, and A. Bationo. 2016. Impact of reduced tillage and crop residue management on soil properties and crop yields in a long-term trial in Western Kenya. Soil Research 54: 719-729.

Palm, C., H. Blanco-Canqui, F. DeClerck, L. Gatere, and P. Grace. 2014. Conservation agriculture and ecosystem services: an overview. Agriculture, Ecosystems and Environment 187: 87-105.

Pittelkow, C., M. X. Liang, B. A. Linquist, K. J. van Groenigen, J. Lee, M. E. Lundy, N. Van Gestel, J. Six, R. T. Venterea and C. van Kessel. 2015. Productivity limits and potentials of the principles of conservation agriculture. Nature 517: 365-368.

Powlson, D. S., C. M. Stirling, C. Thierfelder, R. P. White, and M. L. Jat. 2016. Does conservation agriculture deliver climate change mitigation through soil carbon sequestration in tropical agro-ecosystems? Agriculture, Ecosystems and Environment 220: 164-174.

QSR International Pty Ltd. 2015. NVivo qualitative data analysis software. Version 11. Melbourne, Australia. https://www.qsrinterna tional.com/. Accessed 10 Feb 2019.

Schaller, M., E. Barth, D. Blies, F. Röhrig, and M. Schümmelfeder. 2017. Climate smart agriculture (CSA): conservation agriculture (CA). SLE (Center for Rural Development, Humbolt University), Berlin. https://cgspace.cgiar.org/handle/10568/82728. Accessed 6 Sept 2018

Sorley, C. 2009. Farming that brings Glory to God: a set of biblical principles to transform the practice of agriculture. Nairobi: Care of Creation Kenya.

Spaling, H. 2003. Enabling creation's praise: lessons in agricultural stewardship from Africa. In Biblical holism and agriculture: cultivating our roots, eds. D. Evans, R. Vos, and K. Wright, 99-119. Pasadena: William Carey.
Speranza, C. I. 2013. Buffer capacity: capturing a dimension of resilience to climate change in African smallholder agriculture. Regional Environmental Change 13: 521-535.

Stevenson, J. R., R. Serraj, and K. G. Cassman. 2014. Evaluating conservation agriculture for small-scale farmers in Sub-Saharan Africa and South Asia. Agriculture Ecosystems and Environment 187: $1-10$.

Steward, R., A. J. Dougill, C. Thierfelder, C. M. Pittelkow, L. C. Stringer, M. Kudzala, and G. E. Shackelford. 2018. The adaptive capacity of maize-based conservation agriculture systems to climate stress in tropical and subtropical environments: a metaregression of yields. Agriculture Ecosystems and Environment 251: 194-202.

Sumberg, J., J. Thompson, and P. Woodhouse. 2012. Contested agronomy: agricultural research in a changing world. In Contested agronomy: agricultural research in a changing world, eds. J. Sumberg, and J. Thompson, 1-21. London: Routledge.

Sumberg, J., J. Thompson, and P. Woodhouse. 2013. Why agronomy in the developing world has become contentious. Agriculture and Human Values 30: 71-83.

Sutherland Smith, S. 2013. African farmers reap a harvest of food, faith - and a future. Prism Magazine 20: 19-21.

Thierfelder, C., and P. C. Wall. 2009. Effects of conservation agriculture techniques on infiltration and soil water content in Zambia and Zimbabwe. Soil and Tillage Research 105: 217-227.

Thierfelder, C., and P. C. Wall. 2010. Investigating conservation agriculture (CA) systems in Zambia and Zimbabwe to mitigate future effects of climate change. Journal of Crop Improvement 24: 113-121.

Thierfelder, C., P. Chivenge, W. Mupangwa, T. S. Rosenstock, C. Lamanna, and J. X. Eyre. 2017. How climate-smart is conservation agriculture (CA)?-Its potential to deliver on adaptation, mitigation and productivity on smallholder farms in southern Africa. Food Security 9: 537-560.

Twomlow, S., L. Hove, W. Mupangwa, P. Masikati, and N. Mashingaidze. 2009. Precision conservation agriculture for vulnerable farmers in low-potential zones. In Proceedings of the workshop on increasing the productivity and sustainability of rainfed cropping systems of poor, smallholder farmers, Tamale, Ghana, L. Humphreys (ed.), 22-25 Sept 2008. Colombo, Sri Lanka: The CGIAR Challenge Program on Water and Food.

Van Hulst, Freddy J., and Helena Posthumus. 2016. Understanding (non-) adoption of conservation agriculture in Kenya using the Reasoned Action Approach. Land Use Policy 56: 303-314.

Whitfield, S., A. J. Dougill, J. C. Dyer, F. K. Kalaba, J. Leventon, and L. C. Stringer. 2015. Critical reflection on knowledge and narratives of conservation agriculture. Geoforum 60: 133-142.

Zingore, S., H. K. Murwira, R. J. Delve, and K. E. Giller. 2007. Influence of nutrient management strategies on variability of soil fertility, crop yields and nutrient balances on smallholder farms in Zimbabwe. Agriculture, Ecosystems and Environment 119: 112-126.

Publisher's Note Springer Nature remains neutral with regard to jurisdictional claims in published maps and institutional affiliations.

Harry Spaling $\mathrm{PhD}$, is Professor of Geography \& Environmental Studies at The King's University, Edmonton, Canada. In collaboration with colleagues and students from the Universities of Manitoba and Nairobi, he has conducted applied research on community-based environmental assessment and sustainable resource-based livelihoods in Kenya since 2001. He previously worked in Sierra Leone as a community agriculturalist and national director for World Renew Canada. 
Kendra Vander Kooy completed an internship researching Farming God's Way in Kenya as part of her BA in Environmental Studies and Economics and Politics at The King's University. She is currently employed as a water conservation program liaison promoting municipal water conservation practices and educating the public on the importance of sustainably managing freshwater resources locally and globally. 